\title{
Implementasi Application Programming Interface (API) Google Calendar Sebagai Reminder Informasi Kegiatan Pondok Pesantren
}

\author{
Asep Kurniawan ${ }^{1}$, Alam Rahmatulloh ${ }^{2}$, Heni Sulastri ${ }^{3}$ \\ ${ }^{1,2,3}$ Program Studi Informatika, Universitas Siliwangi \\ Tasikmalaya, Indonesia
}

e-mail: asep.kurniawan14@student.unsil.ac.id, alam@unsil.ac.id, henisulastri@unsil.ac.id

\begin{abstract}
Abstrak
Masyarakat pada saat ini hampir seluruhnya memiliki akun di dunia maya, terutama akun Google sebagai salah satu raksasa internet yang menyediakan berbagai macam fasilitas untuk memudahkan penggunanya, dengan fitur yang disediakan sebagai Application Programming Interface (API) yaitu API Google Calendar merupakan salah satu fasiliitas yang digunakan untuk pengingat (reminder) dan penjadwalan kegiatan. Pondok Pesantren memiliki jadwal kegiatan dan informasi yang harus diketahui oleh anggota Pondok Pesantren sebagai pengetahuan dan panduan kegiatan belajar mengajar atau kegiatan lainya yang akan dilakukan. Pondok Pesantren ini jadwal kegiatan dan informasi dipublikasikan dengan cara manual, maka dibutuhkan suatu sistem yang mengelola jadwal kegiatan dan informasi, serta mempublikasikan menggunakan Google Calendar untuk memberikan pengingat (reminder) atau notifikasi agar tersampaikan kepada anggota Pondok Pesantren. Penelitian ini menggunakan metodologi pengembangan sistem Personal Extreme Programming (PXP) dan hasil dari penelitian ini yaitu API Google Calendar telah berhasil diimplementasikan pada apliksi pesantren reminder, yang dapat mengelola kegiatan dan menyampaikan informasi kegiatan kepada anggota Pondok Pesantren menggunakan Google Calendar.
\end{abstract}

Kata kunci: Application Programming Interface, Google Calendar, Pondok Pesantren, Reminder

\begin{abstract}
The community at this time almost all have accounts in cyberspace, especially Google accounts as one of the internet giants that provide various facilities to make it easier for users, with features provided as Application Programming Interface (API), namely the Google Calendar API is one of the facilities used for reminders and scheduling activities. Islamic Boarding Schools have a schedule of activities and information that must be known by boarding school members as knowledge and guidance on teaching and learning activities or other activities to be carried out. This Islamic Boarding School is scheduled to publish activities and information manually, so we need a system that manages the schedule of activities and information, and publish using Google Calendar to provide reminders (reminder) or notifications to be conveyed to members of Islamic Boarding Schools. This study uses the Personal Extreme Programming (PXP) system development methodology and the results of this research, namely the Google Calendar API have been successfully implemented in reminder boarding applications, which can manage activities and deliver activity information to boarding school members using Google Calendar.
\end{abstract}

Keywords : Application Programming Interface, Google Calendar, Islamic Boarding School, Reminder

\section{PENDAHULUAN}

Teknologi pada saat ini sudah berkembang sangat pesat, kehadiran teknologi membantu manusia untuk menyajikan kemudahan-kemudahan melalui berbagai sarana baik melalui televisi, handphone, dan internet dalam berbagai bidang. Seperti yang di terapkan pada 
bidang pemerintahan, pendidikan, perusahan, dan bidang lainnya.

Masyarakat pada saat ini hampir seluruhnya memiliki akun didunia maya, terutama akun Google sebagai salah satu raksasa internet yang menyediakan berbagai macam fasilitas untuk memudahkan penggunanya. Fasilitas tersebut menjadi penunjang manusia untuk mengembangkan teknologi yang terdapat pada Application Programming Interface (API) Google salah satunya Google Calendar, pengguna dapat memasang pengingat (remainder) yang merupakan salah satu fitur yang ada pada Google Calender. Selain itu, pengguna dapat memanfaatkan fasilitas Google Calendar untuk membuat jadwal kegiatan yang terkoneksi dengan internet dan melakukan sinkronisasi dengan perangkat lainnya.

Kegiatan belajar mengajar Pondok Pesantren Tanjung Resik At-taqwa memiliki jadwal kegiatan dan informasi yang harus diketahui oleh santri dan wali santri sebagai pengetahuan dan panduan kegiatan belajar mengajar atau kegiatan lainya yang akan dilakukan agar berjalan dengan lancar.

Sedangkan di Pondok Pesantren ini jadwal kegiatan dan informasi dipublikasikan dengan cara manual yaitu ditempelkan pada papan pengumuman atau disampaikan langsung kepada orang yang bersangkutan, maka dibutuhkan suatu sistem yang mengelola jadwal kegiatan dan informasi, serta mempublikasikan menggunakan Google Calendar yang tersingkron untuk memberikan pengingat (reminder) atau notifikasi agar tersampaikan kepada anggota Pondok Pesantren.

Permasalahan reminder/sebaran sebelumnya sudah pernah dilakukan diantaranya penelitian [1] mengintegrasikan sistem informasi absensi siswa dengan teknologi SMS Gateway yang dapat mempermudah orang tua siswa dalam mengetahui informasi sekaligus memonitor kehadiran belajar siswa dan membantu pihak sekolah dalam penyampaian kepada wali murid secara tepat dan cepat. Penelitian tersebut menggunkan teknologgi SMS Gateway, sedangkan teknologi SMS pada saat ini sudah jarang di gunakan atau mulai di tinggalkan oleh kebanyakan orang indonesia dan teknologi SMS Gateway memerlukan provider berbayar untuk mengirimkan SMS kepada penggunanya sehigga teknologi SMS Gateway memerlukan biaya sesuai ketentuan provider sedangkan Google Calendar menyediakan fasilitas gratis, maka penelitian kali ini akan mengimplmentasikan teknologi Google Calendar.

\section{LANDASAN TEORI Reminder/Notifikasi}

Menurut [2] Reminder/Peringatan merupakan nasihat (teguran dan sebagainya) untuk memperingatkan, notifikasi adalah pesan yang muncul secara otomatis dalam perangkat digital kepada pemilik sebuah akun (media sosial, aplikasi daring, rekening bank, dan sebagainya). Reminder atau Notifikasi berbentuk pesan untuk mengingatkan seseorang dalam mengingat sesuatu hal. Reminder lebih bermanfaat ketika digunakan untuk menyajikan informasi pada waktu dan tempat yang tepat, dengan cara memasang alarm peringatan berupa catatan berisi informasi dan waktu, serta lokasi.

\section{Informasi}

Informasi merupakan sekumpulan data yang diproses untuk membantu dalam pengambilan keputusan dan merupakan bagian penting dari sistem. Informasi dapat mempengaruhi kualitas sistem, dengan informasi yang baik sistem dapat berfungsi dengan baik pula. Informasi berkualitas harus mempunyai tiga unsur berikut [3] :

1. Akurat, berarti informasi harus jelas, tidak bias atau menyesatkan. Informasi juga harus akurat agar penerima informasi dapat mencerna maksud dari informasi yang diberikan oleh pengirim.

2. Tepat waktu, informasi harus selalu dapat diambil penerima dengan cepat. Informasi yang sudah using tidak akan mempunyai arti.

3. Relavan. Berarti informasi tersebut mempunyai manfaat bagi pemakainya.

Informasi merupakan Output dari data yang telah diolah sedemikian rupa hingga menjadi suatu bentuk yang berguna dan telah mempunyai arti. Output yang tidak memiliki tiga unsur diatas (Akurasi, Tepat Waktu, Relevan) dapat dikatakan sebagai informasi yang berguna, tetapi merupakan sampah. 


\section{Pondok Pesantren}

Menurut asal katanya pesantren berasal dari kata "santri" yang dibubuhi imbuhan "pe" dan "an" yang menunjukkan tempat, maka artinya adalah tempat para santri. Terkadang pula pesantren dapat diartikan dengan tempat pendidikan manusia baikbaik yang diambil dari kata "santri" (manusia baik) dan suku kata "tra" (suka menolong) [4].

Pesantren juga dikenal dengan tambahan istilah pondok yang dalam arti kata bahasa Indonesia mempunyai arti kamar, gubug, rumah kecil dengan menekankan kesederhanaan bangunan atau pondok juga berasal dari bahasa Arab "Fundũq" yang berarti ruang tidur, wisma, hotel sederhana, atau mengandung arti tempat tinggal yang terbuat dari bambu [4]. Pondok pesantren dapat diartikan sebagai tempat atau komplek para santri dalam belajar atau mengaji ilmu pengetahuan agama kepada kiai atau guru ngaji, biasanya komplek itu berbentuk asrama atau kamar-kamar kecil dengan bangunan apa adanya yang menunjukkan kesederhanaannya.

\section{Google Calendar}

Aplikasi ini diluncurkan pada 13 April 2006 dan secara umum dirilis pada bulan Juli 2009, di web dan sebagai aplikasi seluler untuk platform Android dan iOS. Pengguna perlu memiliki Google Account untuk menggunakan perangkat lunak ini dan dapat melakukan pengelolaan waktu dengan berbasiskan web.

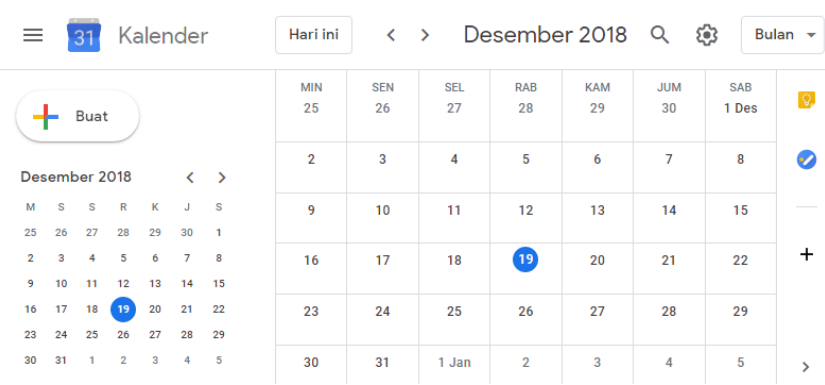

Gambar 1 Google Calendar

Gambar 1 Google calendar memiliki beberapa fitur sebagai berikut [5]:

a. Jadwalkan acara

Google calendar, mudah untuk menjadwalkan suatu aktivitas, seperti konferensi, serta acara rutin, seperti rapat staf. Saat menerima undangan ke suatu acara, dapat memberi tahu semua orang jika hadir.

b. Buat pengingat

Untuk mengingat sesuatu di daftar tugas, dapat tambahkan pengingat: membuat pengingat, mengubah pengingat, dan menyelesaikan atau menghapus pengingat.

c. Bagikan dan lihat kalender

Bagikan kalender dengan rekan kerja, keluarga, dan teman-teman agar mereka dapat dengan mudah melihat ketika tersedia, dan dapat melihat kalender orang lain untuk melakukan hal yang sama.

d. Kustomisasi kalender Anda

Setelah tahu cara menggunakan semua fitur utama di Google Calendar, dapat menyesuaikannya lebih jauh agar sesuai dengan cara bekerjanya: Kelola notifikasi acara, pilih tampilan kalender, ubah tampilan kalender.

\section{API Google Calendar}

API Calendar adalah API REST yang dapat diakses melalui panggilan explicit HTTP atau melalui Google Client Libraries, API menampilkan sebagian besar fitur yang tersedia di antarmuka Web Google Calendar [6].

\section{Penelitian Terkait}

Penelitian terkait pada penelitian ini antara lain :

1. Penelitian [7] telah berhasil mengimplementasikan Application Programming Interface (API) Google pada sistem manajemen arsip sebagai media penyimpanan datanya.

2. Penelitian ini membangun sebuah aplikasi untuk mengelola acara kegiatan di Universitas Muhammadiyah Surakarta (UMS) dengan menggunakan Google Application API. Aplikasi ini dapat mempublikasikan jadwal perkuliahan sebagai pelengkap dari Aplikasi Jadwal Terpadu yang sudah ada dan menambahkan fitur untuk mengelola agenda kegiatan lainnya [7].

3. Penelitian ini merancang aplikasi bimbingan Tugas Akhir memanfaatkan Google Calendar yang dapat membantu mempermudah proses penjadwalan pertemuan bimbingan Tugas Akhir [8].

4. Penelitian ini membuat sebuah sistem monitoring jaringan dengan mengirimkan 
pemberitahuan berupa SMS dengan memanfaatkan fasilitas SMS alert dari Google Calendar yang memiliki kemampuan dalam mengecek status perangkat jaringan setiap 5 menit dan jika terjadi perubahan status perangkat [9].

5. Penelitian ini membuat sistem untuk memudahkan pengguna mencari informasi menggunakan Google Calendar mengenai kegiatan (akan datang/telah terjadi) yang ada di Universitas Kristen Petra [10].

6. Penelitian ini merancang sistem penjadwalan menggunakan Google Calendar untuk dasar acuan manajemen penggunaan ruangan [11].

7. Penelitian ini membuat sistem absensi menggunakan SMS Gateway yang secara otomatis memberikan pemberitahuan kepada orang tua siswa tentang kehadiran [1].

\section{METODE}

Pengembangan perangkat lunak yang digunakan yaitu Extreme Programming $(X P)$ [12]. Pengembangan perangkat lunak dengan situasi pengembangan sistem oleh pemrogram tunggal dapat menggunakan metode Personal Extreme Programming $(P X P)$ [13]. PXP terdiri dari beberapa fase, yaitu requirements, planning, iteration initialization, design, implementation, system testing, dan retrospective [14].

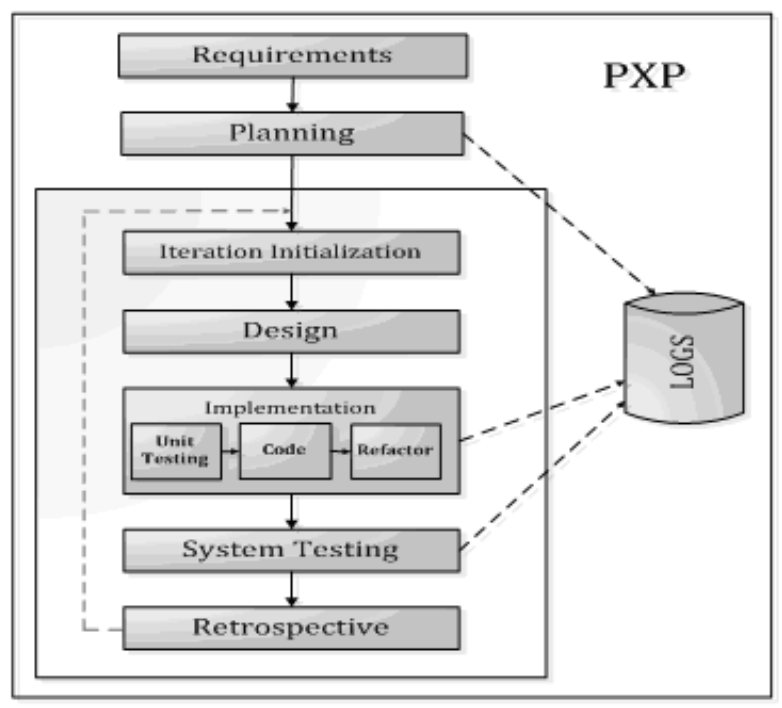

Gambar 2 Personal Extreme Programming [14]
Penjelasan dari tiap fase $P X P$ pada Gambar 2 Personal Extreme Programming (PXP) berikut:

1. Requirements

Requirements merupakan fase identifikasi pengguna sistem, dilanjutkan dengan analisis tekstual.

2. Planning

Fase planning merupakan tahapan untuk menentukan waktu, fungsionalitas, dan kebutuhan keseluruhan yang akan dikembangkan dalam sistem.

3. Iteration Initialization

Fase Iteration initialization merupakan fase fungsionalitas yang sudah dibentuk pada fase planning yang kemudian dijabarkan menjadi terperinci dalam bentuk Unified Modeling Language (UML).

4. Design

Fase Design merupakan fase untuk mulai melakukan desain sistem, mulai dari desain Unified Modeling Language (UML) dan desain antarmuka.

5. Implementation

Fase ini mulai melakukan pengodean sistem yang kemudian dilakukan pengujian unit testing, apabila ada kesalahan maka dilakukan refactor atau koreksi ulang pada tahap dimana kesalahan tersebut bermula, apabila tidak ada kesalahan maka dilanjutkan ke unit selanjutnya.

6. System Testing

Pada fase ini dilakukan pengujian pada semua fungsionalitas untuk mengetahui apakah masih ada kekurangan atau sudah cukup menggunakan teknik Black Box Testing.

7. Retrospective

Pada fase ini sistem disimpulkan, apabila masih ada kesalahan maka akan dilakukan perbaikan mulai dari tahap iteration initialization.

\section{HASIL DAN PEMBAHASAN \\ Requirements}

A. Pengguna sistem

Pengguna Sistem ini adalah admin (pengelola sistem) dan diterima oleh penerima (guru,santri,wali) atau anggota Pondok Pesantren.

B. Analisis Tekstual 
Sistem ini diharapkan dapat membantu pihak Pondok Pesantren untuk menyampaikan jadwal kegiatan dan informasi. Memudahkan anggota Pondok Pesantren menerima informasi dan jadwal kegiatan tanpa harus mecari atau menanyakan langsung kepada pihak Pondok Pesantren. Admin atau pihak Pondok Pesantren membuat/menambahkan kegiatan dengan waktu dan informasi tertentu pada sistem kemudian sistem mingirim ke Google Calendar. Setelah kegiatan ditambahkan, selanjutnya Google calendar akan mengirim reminder/notifikasi informasi dan jadwal kegiatan sesuai apa yang dibuat/ditambahkan pada sistem kepada anggota Pondok Pesantren yaitu guru, santri, dan wali yang tersingkron Google atau menggunakan Google Calendar.

\section{Planning}

Kebutuhan Sistem

Spesifikasi kebutuhan yang diperlukan untuk membuat aplikasi Pesantren Reminder adalah sebagai berikut:

1. Kebutuhan Masukan : Kegiatan yang akan disampaikan kepada anggota Pondok Pesantren yaitu judul, waktu, dan deskripsi.

2. Kebutuhan Keluaran : Mengirimkan reminder/notifikasi informasi kegiatan dengan menggunakan API Google Calendar kepada anggota Pondok Pesantren.

3. Kebutuhan Bisnis : Pada kebutuhan bisnis terbagi menjadi 2 bagian yaitu kebutuhan perangkat keras dan perangkat lunak, dapat di lihat pada Tabel 1.

Tabel 1 Kebutuhan perangkat keras dan lunak

\section{Iteration Initialization}

\section{Use Case}

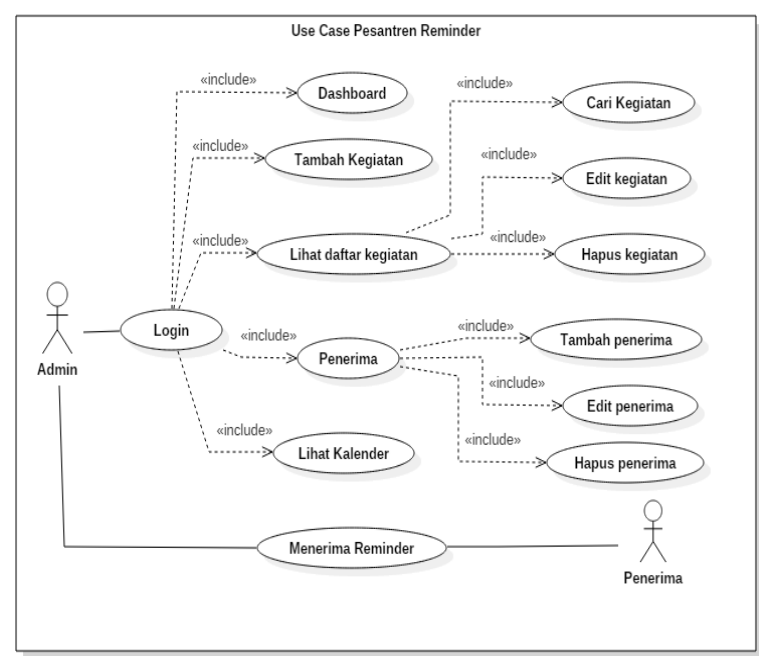

Gambar 3 Use Case Diagram

2. Identifikasi Aktor

Aktor dari aplikasi yang akan dibangun, terdiri dari beberapa aktor yaitu: Admin (Pengelola Sistem) dan aktor Penerima (Guru/Santri/Wali), dapat dilihat pada Tabel 2.

Tabel 2 Identifikasi Aktor

\begin{tabular}{|l|lr|}
\hline \multicolumn{1}{|c|}{ Aktor } & \multicolumn{2}{c|}{ Deskripsi } \\
\hline Admin & Admin adalah orang yang \\
(Pengelola & akan $r$ menggunakan \\
Sistem) & sistem atau \\
& mengoprasikan sistem \\
& dan mengelola sistem \\
& untuk mengirim reminder \\
& kepada r penerima \\
& reminder dari sistem. \\
\hline $\begin{array}{l}\text { Penerima } \\
\text { (Guru/Santri/ }\end{array}$ & $\begin{array}{l}\text { Penerima Sistem adalah } \\
\text { Wali) }\end{array}$ & orang yang menerima \\
& reminder dari sistem, \\
& penerima yang akan \\
& menerima reminder \\
& harus menggunakan \\
& Google Calendar. \\
\hline
\end{tabular}

\section{Design}

\begin{tabular}{|c|c|}
\hline Perangkat Keras & Perangkat Lunak \\
\hline $\begin{array}{ll}\text { 1. } & \text { CPU 2.20 GHz } \\
\text { 2. } & \text { RAM 4 GB } \\
\text { 3. } & \text { Hardisk 200GB } \\
\text { 4. } & \text { Monitor } 15 \text { inch }\end{array}$ & $\begin{array}{ll}\text { 1. } & \text { Web Server Apache } \\
\text { 2. } & \text { Web Browser } \\
\text { 3. } & \text { Sublime Text Editor } \\
\text { 4. } & \text { StarUML } \\
\text { 5. } & \text { Balsamiq mockups } \\
\text { 6. } & \text { Mysql }\end{array}$ \\
\hline
\end{tabular}


menggambarkan perancangan antarmuka halaman dashboard.

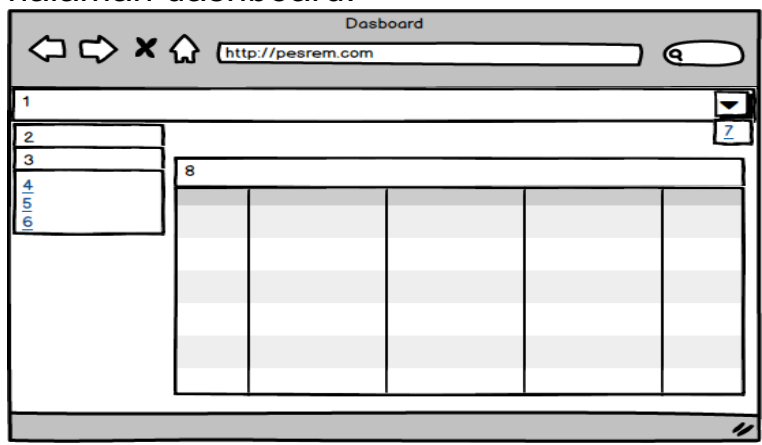

Gambar 4 Perancangan antarmuka halaman Dashboard

Keterangan dari Gambar 4 yaitu 1.teks nama aplikasi pesantren reminder, 2.teks dasboard, 3.teks kegiatan, 4.tombol tambah kegiatan untuk ke halaman tambah kegiatan, 5.tombol daftar kegiatan untuk ke halaman daftar kegiatan, 6.tombol penerima untuk ke halaman penerim, 7.tombol keluar untuk pengguna keluar dari aplikasi, 8.menampilkan isi halaman dashboard dan menampilkan daftar kegiatan dalam bentuk tabel.

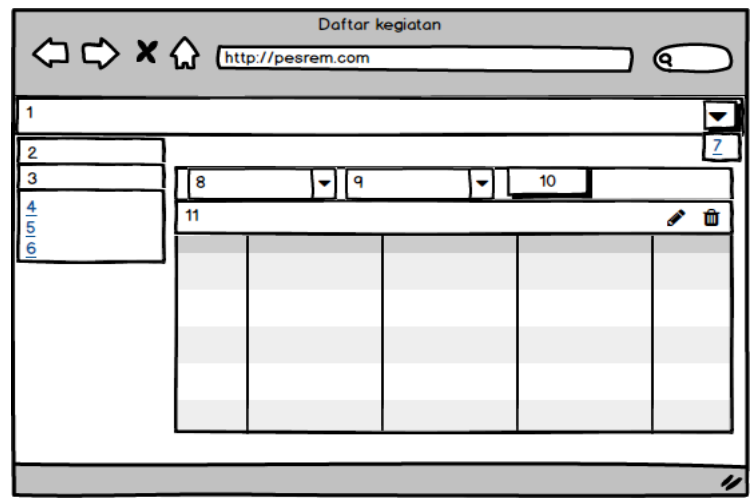

Gambar 5 Perancangan antarmuka halaman Daftar kegiatan

Keterangan dari Gambar 5 yaitu sama dengan halaman dashboard, dan pada halaman dafrtar kegiatan terdapat tombol cari, edit, dan hapus kegiatan.

\section{Implementation}

Pada tahap ini, mulai dilakukan pengodean sistem dan menampilkan hasil dari implementasi.

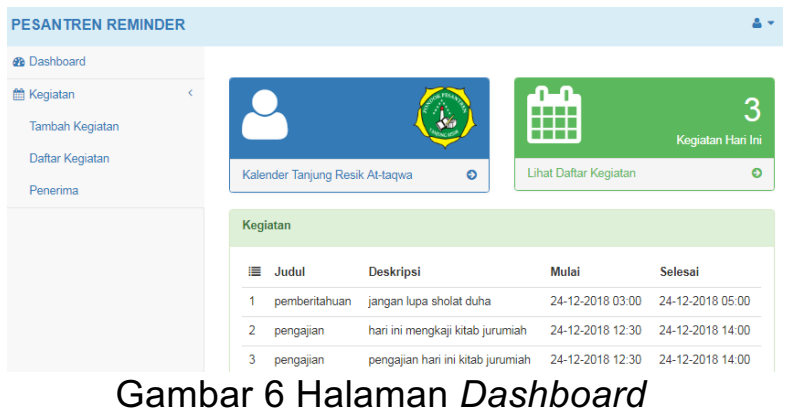

Gambar 6 merupakan tampilan halaman utama aplikasi. Pada halaman dashboard terdapat menu tambah kegiatan, daftar kegiatan, penerima, dan logout. Halaman dashboard juga menampilkan daftar kegiatan.

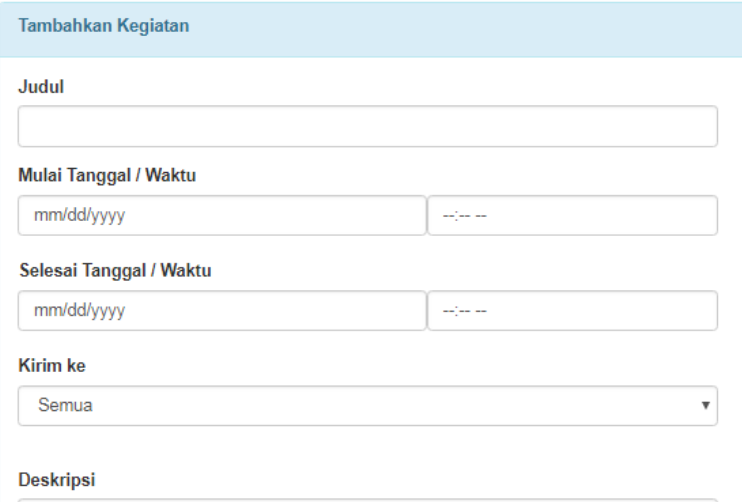

\section{Simpan}

Gambar 7 Halaman Tambah kegiatan

Gambar 7 merupakan tampilan halaman untuk menambahkan kegiatan. Terdapat menu seperti halaman dashboard. Halaman tambah kegiatan menampilkan form input judul, tanggal/waktu, kirim ke, dan deskripsi untuk diisi oleh admin.

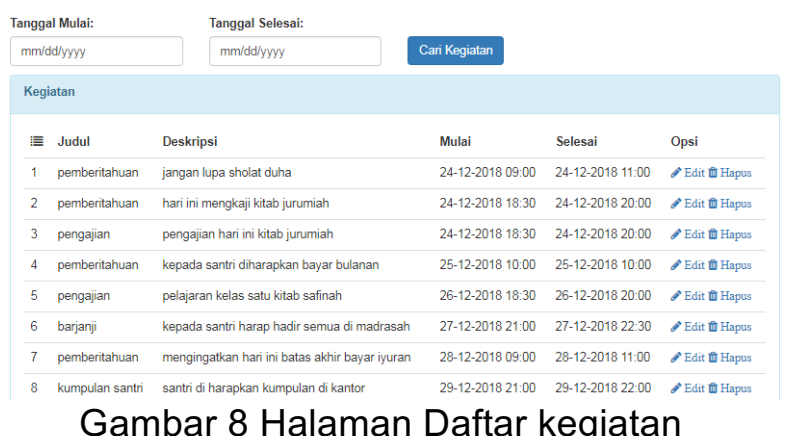


Gambar 8 merupakan tampilan halaman untuk menampilkan daftar kegiatan. Terdapat menu seperti halaman dashboard. Halaman daftar kegiatan terdapat tombol-tombol untuk melakukan cari kegiatan, merubah kegiatan, dan menghapus kegiatan.

\begin{tabular}{|c|c|c|c|c|}
\hline \multicolumn{3}{|c|}{ Penerima } & \multicolumn{2}{|c|}{ +Tambah penerima } \\
\hline 㭋 & Nama & Email & Level & Opsi \\
\hline 1 & Asep Kurniawan & askur2311@gmail.com & Guru & Edit 1 Hapus \\
\hline 2 & Ridwan Nurgomar & ridwannurqomar@gmail.com & Wali & Edit 1 Hapus \\
\hline 3 & Ade Solihin & adesolihin79@gmail.com & Santri & Edit 1 Hapus \\
\hline 4 & abduloh & abdulohguru@gmail.com & Guru & Edit Hapus \\
\hline 5 & Mustofa & mustofawali@gmail.com & Wali & Edit 1 Hapus \\
\hline 6 & angga & anggasantri1@gmail.com & Santri & Edit 10 Hapus \\
\hline
\end{tabular}

Gambar 9 Halaman Penerima

Gambar 9 merupakan tampilan halaman untuk menampilkan penerima reminder. Terdapat menu seperti halaman dashboard. Halaman penerima terdapat tombol-tombol untuk melakukan tambah penerima, merubah penerima, dan menghapus penerima.

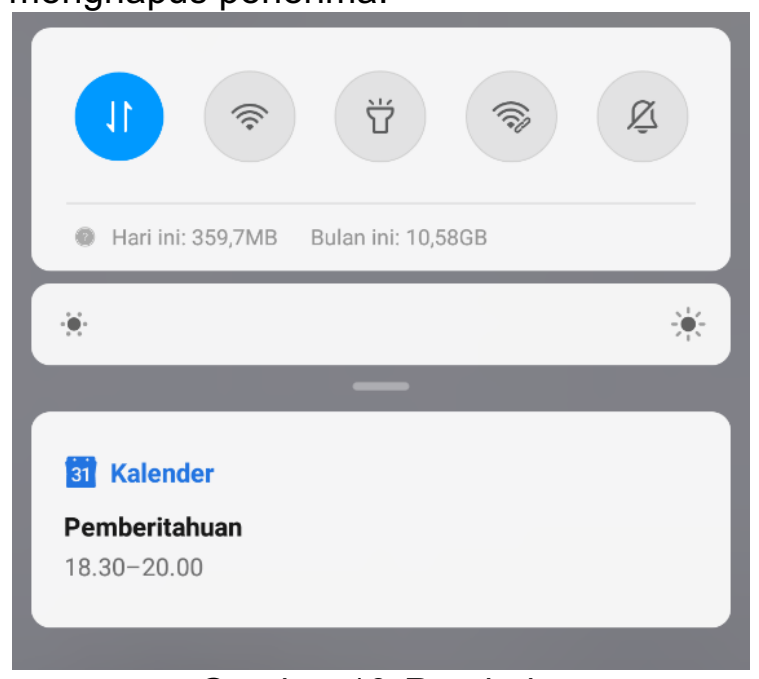

\section{Gambar 10 Reminder}

Gambar 10 merupakan reminderl notifikasi pada platform mobile penerima atau anggota Pondok Pesantren menggunakan Google Calendar.

\section{$x$ \\ - pemberitahuan \\ Hari ini $\cdot 18.30-20.00$

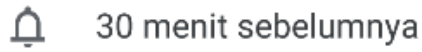 \\ 온 2 tamu 2 menunggu tanggapan \\ abdulohguru@gmail.com \\ asep kurniawan \\ $\equiv$ hari ini mengkaji kitab jurumiah \\ Gambar 11 Detail Reminder}

Gambar 11 merupakan tampilan halaman detail reminder pada platform mobile penerima atau anggota Pondok Pesantren yang menggunakan Google Calendar. Menampilkan judul kegiatan, waktu kegiatan, tamu kegiatan/penerima kegiatan, dan deskripsi kegiatan.

\section{System Testing}

Metode yang digunakan dalam pengujian sistem yaitu menggunakan teknik Black Box Testing dengan cara menguji sistem dari segi spesifikasi fungsional tanpa menguji desain dan kode program dengan maksud untuk mengetahui apakah fungsifungsi, masukan, dan keluaran dari perangkat lunak sudah sesuai dengan spesifikasi awal yang direncanakan dan sesuai dengan kebutuhan.

Tabel 3 halaman tambah kegiatan

\begin{tabular}{|l|l|l|l|}
\hline $\begin{array}{l}\text { Langkah } \\
\text { pengujian }\end{array}$ & $\begin{array}{l}\text { Hasil yang } \\
\text { diharapkan }\end{array}$ & $\begin{array}{l}\text { Hasil } \\
\text { pengujian }\end{array}$ & $\begin{array}{l}\text { Respon } \\
\text { program }\end{array}$ \\
\hline $\begin{array}{l}\text { Memilih } \\
\text { menu } \\
\text { tambah } \\
\text { kegiatan }\end{array}$ & $\begin{array}{l}\text { Menampilka } \\
\text { n form isian } \\
\text { tambah } \\
\text { kegiatan }\end{array}$ & $\begin{array}{l}\text { Aplikasi } \\
\text { menampilk } \\
\text { an } \\
\text { halaman } \\
\text { form isian } \\
\text { tambah } \\
\text { kegiatan }\end{array}$ & $\begin{array}{l}{[\sqrt{ }]} \\
\text { Diterima }\end{array}$ \\
{$[$ ] Ditolak } \\
\hline $\begin{array}{l}\text { Ditambahka } \\
\text { n kegiatan } \\
\text { baru, klik }\end{array}$ & $\begin{array}{l}\text { Kegiatan } \\
\text { baru } \\
\text { disimpan }\end{array}$ & $\begin{array}{l}\text { Aplikasi } \\
\text { menyimpa }\end{array}$ & $\begin{array}{l}{[\sqrt{ }]} \\
\text { Diterima }\end{array}$ \\
\hline
\end{tabular}




\begin{tabular}{|l|l|l|l|}
\hline $\begin{array}{l}\text { tombol } \\
\text { "Simpan" }\end{array}$ & $\begin{array}{l}\text { n kegiatan } \\
\text { baru }\end{array}$ & [ ] Ditolak \\
\hline
\end{tabular}

Tabel 4 halaman penerima

\begin{tabular}{|c|c|c|c|}
\hline $\begin{array}{l}\text { Langkah } \\
\text { Pengujian }\end{array}$ & $\begin{array}{l}\text { Hasil yang } \\
\text { diharapkan }\end{array}$ & $\begin{array}{c}\text { Hasil } \\
\text { pengujian }\end{array}$ & $\begin{array}{l}\text { Respon } \\
\text { program }\end{array}$ \\
\hline $\begin{array}{l}\text { Memilih } \\
\text { menu } \\
\text { Penerima }\end{array}$ & $\begin{array}{l}\text { Menampilka } \\
\mathrm{n} \text { halaman } \\
\text { penerima }\end{array}$ & $\begin{array}{l}\text { Aplikasi } \\
\text { menampilka } \\
\text { n halaman } \\
\text { penerima }\end{array}$ & $\begin{array}{l}{[\sqrt{ }]} \\
\text { Diterima } \\
\text { [ ] Ditolak }\end{array}$ \\
\hline $\begin{array}{l}\text { Memilih } \\
\text { tombol } \\
\text { "Tambah } \\
\text { penerima" }\end{array}$ & $\begin{array}{l}\text { Menampilka } \\
\mathrm{n} \text { form isian } \\
\text { tambah } \\
\text { penerima }\end{array}$ & $\begin{array}{l}\text { Aplikasi } \\
\text { menampilka } \\
\mathrm{n} \text { halaman } \\
\text { form isian } \\
\text { tambah } \\
\text { penerima }\end{array}$ & $\begin{array}{l}\sqrt{ }] \\
\text { Diterima } \\
\text { [ ] Ditolak }\end{array}$ \\
\hline $\begin{array}{l}\text { Ditambahk } \\
\text { an } \\
\text { penerima } \\
\text { baru, klik } \\
\text { tombol } \\
\text { "Tambah" }\end{array}$ & $\begin{array}{l}\text { Penerima } \\
\text { baru } \\
\text { disimpan }\end{array}$ & \begin{tabular}{|l} 
Aplikasi \\
menyimpan \\
penerima \\
baru
\end{tabular} & $\begin{array}{l}\sqrt{ }] \\
\text { Diterima } \\
\text { [ ] Ditolak }\end{array}$ \\
\hline $\begin{array}{l}\text { Merubah } \\
\text { penerima, } \\
\text { klik tombol } \\
\text { "Edit" }\end{array}$ & $\begin{array}{l}\text { Menampilka } \\
\mathrm{n} \text { form edit } \\
\text { penerima }\end{array}$ & $\begin{array}{l}\text { Aplikasi } \\
\text { menampilka } \\
\mathrm{n} \text { halaman } \\
\text { form edit } \\
\text { penerima }\end{array}$ & $\begin{array}{l}{[\sqrt{ }]} \\
\text { Diterima } \\
\text { [ ] Ditolak }\end{array}$ \\
\hline $\begin{array}{l}\text { Melakukan } \\
\text { perubahan } \\
\text { pada } \\
\text { penerima, } \\
\text { klik tombol } \\
\text { "edit" }\end{array}$ & $\begin{array}{l}\text { Penerima } \\
\text { berubah } \\
\text { dan berhasil } \\
\text { disimpan }\end{array}$ & $\begin{array}{l}\text { Perubahan } \\
\text { penerima } \\
\text { berhasil } \\
\text { disimpan }\end{array}$ & $\begin{array}{l}\text { [ } \sqrt{ }] \\
\text { Diterima } \\
\text { [ ] Ditolak }\end{array}$ \\
\hline $\begin{array}{l}\text { Melakukan } \\
\text { penghapus } \\
\text { an salah } \\
\text { satu dari } \\
\text { penerima, } \\
\text { klik tombol } \\
\text { "Hapus" }\end{array}$ & $\begin{array}{l}\text { Aplikasi } \\
\text { menampilka } \\
\text { n pesan } \\
\text { konfirmasi } \\
\text { sebelum di } \\
\text { menghapus }\end{array}$ & $\begin{array}{l}\text { Pesan } \\
\text { konfirmasi } \\
\text { ditampilkan }\end{array}$ & $\begin{array}{l}{[\sqrt{ }]} \\
\text { Diterima } \\
\text { [ ] Ditolak }\end{array}$ \\
\hline $\begin{array}{l}\text { Memilih } \\
\text { tombol } \\
\text { "Oke" }\end{array}$ & \begin{tabular}{|l} 
Aplikasi \\
menghapus \\
penerima \\
dan \\
menampilka \\
n halaman \\
Penerima
\end{tabular} & \begin{tabular}{|l} 
Penerima \\
terhapus \\
dan \\
menampilka \\
n halaman \\
Penerima
\end{tabular} & $\begin{array}{l}\sqrt{ } \text { ] } \\
\text { Diterima } \\
\text { [ ] Ditolak }\end{array}$ \\
\hline
\end{tabular}

Berdasarkan hasil pengujian Tabel 3 dan 4 yang telah dilakukan menunjukkan bahwa sistem yang dibangun berfungsi sesuai dengan yang di harapkan, informasi kegiatan yang dikelola oleh admin dapat tersampaikan kepada anggota Pondok Pesantren.
Pengujian Round Trip Time (RTT), RTT adalah waktu yang dibutuhkan sebuah paket untuk melakukan perjalanan dari sumber ke tujuan dan kembali lagi [16] [17].

Tabel 5 Pengujian RTT

\begin{tabular}{|c|c|c|c|}
\hline No & Send $(\mathrm{ms})$ & Receive $(\mathrm{ms})$ & $R T T(\mathrm{~ms})$ \\
\hline 1 & 0,26 & 4,16 & 3,9 \\
\hline 2 & 0,29 & 15,04 & 14,75 \\
\hline 3 & 0,38 & 6,6 & 6,22 \\
\hline 4 & 1,63 & 11,4 & 9,77 \\
\hline 5 & 0,52 & 7,47 & 6,95 \\
\hline 6 & 0,24 & 8,03 & 7,79 \\
\hline 7 & 0,22 & 8,56 & 8,34 \\
\hline 8 & 0,26 & 14,98 & 14,72 \\
\hline 9 & 0,5 & 17,35 & 16,85 \\
\hline 10 & 0,14 & 9,82 & 9,68 \\
\hline AVG & $\mathbf{0 , 4 4 4}$ & $\mathbf{1 0 , 3 4 1}$ & $\mathbf{9 , 8 9 7}$ \\
\hline
\end{tabular}

Pengujian menggunakan fitur devtools pada browser bawaan Google, dengan memanfaatkan menu network untuk mengecek timing/waktunya. Hasilnya bisa dilihat pada Tabel 5 dan Gambar 12.

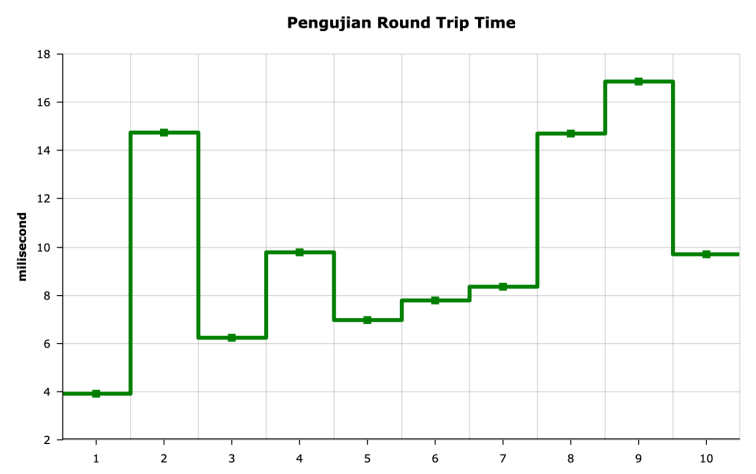

Gambar 12 Pengujian Round Trip Time

Pengujian ini untuk mengetahui kecepatan menambahkan kegiatan, pengujian dilakukan dengan melakukan 10 kali penambahan kegiatan. Terlihat bahwa waktu rata-rata pengiriman (send) adalah $0,444 \mathrm{~ms}$ dan penerimaan (receive) adalah 10,341 ms sedangkan waktu RTT dengan nilai rata-rata 9,897 ms, kecepatan tersebut juga dipengaruhi oleh kestabilan koneksi internet. 


\section{Retrospective}

Tahap ini menyimpulkan bahwa dari tahapan-tahapan yang telah dilakukan seperti tahapan iteration initialization, design, implementation, dan system testing telah sesuai dengan yang diharapkan, sistem dapat berfungsi sebagai pengelola informasi dan jadwal kegiatan Pondok Pesantren.

Hasil penelitian memiliki kelebihan diantaranya :

1. Aplikasi ini tidak memerlukan media penyimpanan kegiatan yang dibuat, otomatis memanfaatkan layanan $A P I$ Google calendar.

2. Aplikasi ini dapat mengirim reminder secara berkelompok tidak harus menulis satu persatu email penerima atau langsung mengirim ke semua penerima seperti default Google calendar.

3. Penggunaan teknologi API Google calendar membantu Pondok Pesantren melakukan penekanan biaya yang harus dikeluarkan untuk mengirim sebaran/reminder kepada anggota Pondok Pesantrennya.

\section{SIMPULAN}

Berdasarkan hasil penelitian yang telah dilakukan dan uraian yang telah dibahas sebelumnya, dapat disimpulkan sebagai berikut:

1. Google Calendar telah berhasil dimanfaatkan dan diimplementasikan pada aplikasi pesantren reminder menggunakan Application Programming Interface (API) Google Calendar, yang dapat mengelola kegiatan dan menyampaikan informasi kegiatan kepada anggota Pondok Pesantren menggunakan Google Calendar.

2. Jadwal kegiatan dan informasi Pondok Pesantren dapat dipublikasikan dengan mengirim reminder kepada anggota Pondok Pesantrennya tanpa mengeluarkan biaya karena menggunakan API Google calendar.

Adapun saran pengembangan pada aplikasi Pesantren Reminder ini. Peneliti selanjutnya disarankan untuk menerapkan lebih banyak fasilitas API Google pada layanan lain untuk diterapkan pada aplikasi Pesantren Reminder, seperti layanan API Google Maps untuk penempatan lokasinya dan dapat di gabungkan dengan teknologi yang lainnya.

\section{DAFTAR PUSTAKA}

[1] S. Hartati, A. Ikwan and R. A. Pradana, "Pengembangan Aplikasi SMS Gateway Berbasis Media Penyampaian Data Kehadiran Siswa Pada Orang Tua," Jatisi, pp. 187-193, 2018.

[2] K. B. B. I. Online, "Kamus Besar Bahasa Indonesia Online," 21 September 2018. [Online]. Available: https://kbbi.kemdikbud.go.id.

[3] H. M. Jogiyanto, Analisis dan Desan, Yogyakarta: Penerbit Andi, 2005.

[4] A. S. Zarkasyi M A, "Peran dan Budaya Islam dalam Mendorong Perkembangan IPTEK (Sebuah Model dari Pondok Modern Gontor," 21 September 2018. [Online]. Available: http://gontor.co.id.

[5] Google, "G Suite Pusat Pembelajaran," 26 September 2018. [Online]. Available: https://gsuite.google.com/learningcenter/products/calender/get-started.

[6] google, "Ihtisar API Kalender," 26 September 2018. [Online]. Available: https://developers.google.com/calendar/co ncepts/.

[7] I. Sontana, A. Rahmatulloh and A. N. Rachman, "Application Programming Interface Google Picker Sebagai Penyimpanan Data Sistem Informasi Arsip Berbasis Cloud," Jurnal Nasional Teknologi dan Sistem Informasi, vol. 5, no. 1, pp. 2532, 2019.

[8] Suyadi and A. G, "Aplikasi Kalender Untuk Pengelolaan Jadwal Kegiatan Kampus dengan Google Application API," in The 5TH URECOL, Yogyakarta, 2017.

[9] I. S. Wulan Rosari and C. Dewi, "Perancangan Aplikasi Bimbingan Tugas AKhir Memanfaatkan Google Calender 
Studi Kasus FTI-UKSW," Universitas Kristen Satya Wacana Salatiga, 2016.

[10] Y. Ferdiansyah, "Repository Universitas Bengkulu," 26 September 2018. [Online]. Available:

repository.unib.ac.id/9222/1/I,II,III.

[11] D. C. LInggadihardja, A. Handojo and A. Wibowo, "Pembuatan Aplikasi "PETRA THEN AND NOW" Tentang Semua Kegiatan di Universitas Kristen Petra," INFRA, 2015.

[12] M. W. Mustika and N. A. Setiawan, "Perancangan Sistem Penjadwalan untuk Manajemen Penggunaan Ruangan Berbasis Google Calendar," Fakultas Teknik Universitas Gadjah Mada, pp. 628633, 2018.

[13] R. S. Pressman, Software Engineering (7th ed), New York: McGraw-Hill, 2010.

[14] R. Agarwal and D. Umphress, "Extreme Programming for a SIngle Person Team," in ACM-SE 46 Proceedings of the 46th Annual Southeast Regional Conference on XX, Auburn, Alabama, 2008.

[15] Y. Dzhurov, I. Krasteva and S. Ilieva, "Personal Extreme Programming-An Agile Process for Autonomous Developers," reaserchgate.net, pp. 252-259, Januari 2009.

[16] H. Husen, A. Rahmatulloh and H. Sulastri, "Implementasi Komunikasi Full Duplex Menggunakan Sistem Informasi Pengelolaan Anggaran Universitas ABC," Simetris: Jurnal Teknik Mesin, Elektro dan Ilmu Komputer, vol. 9, no. 1, pp. 597-606, 1 42018.

[17] E. M. A. Reyouchi, K. Ghoumid, K. Amezian and O. E. Mrabet, "Performance Analysis of Round Trip Time in Narrowband RF Networks For Remote Wireless Communications," International Journal of Computer Science \& Information Technology (IJCSIT), pp. 1-20, 2013. 